\title{
Algumas considerações sobre a imigração nas páginas do jornal Folha do Oeste (1946-1960)
}

Considerations on immigration in Folha do Oeste (1946-1960)

\author{
Rodrigo dos Santos* \\ digao_santos9@hotmail.com
}

Resumo: O presente artigo tem como objetivo discutir a imigração do pós-Segunda Guerra Mundial para o Brasil, no período de 1946 a 1960, através do jornal Folha do Oeste. O referido periódico, produzido no Município de Guarapuava-PR, está disponível no Centro de Documentação e Memória de Guarapuava. Ademais, se utilizará o processo $n^{\circ} .5994$ de 30 de junho de 1950, disponível online no Arquivo de São Paulo.

Palavras-Chave: história da imprensa, imigração do pós-guerra, periódicos

Abstract: This article aims to discuss the post-World War immigration to Brazil, from 1946 to 1960, throughout the West Folha newspaper. The cited journal, produced in Guarapuava-PR, is available in the Documentation Centre and Guarapuava memory. Also, as a source, the paragraph process no. 5994 of June 30, 1950, available online at São Paulo File.

Keywords: history of newspaper, post-war immigration, journals 


\section{Introdução}

O presente artigo discute alguns elementos sobre a imigração do pós- Segunda Guerra, especificamente ao Município de Guarapuava, Paraná no período entre 1946 e 1960. ${ }^{1}$ O semanário Folha do Oeste foi produzido no Município de Guarapuava-PR entre 1937 e 1981, possuindo relevância devido ao seu período de publicação, mais de quarenta anos, pela extensão de sua circulação, vários municípios e Estados. Além disso, em vários momentos foi o único semanário do município. ${ }^{2}$ Além do referido periódico, utilizou-se o processo $\mathrm{n}^{\mathrm{o}}$ 5994 de 1950 da Delegacia de Ordem Política e Social de Santos-SP (DOPS) disponível no Arquivo Público do Estado de São Paulo ${ }^{3}$, e uma matéria do Diário do Paraná, disponível no acervo online da Hemeroteca Digital da Biblioteca Nacional.

A análise dos periódicos foi pautada pelos pressupostos de Luca (2014). Sendo eles: encontrar as fontes e constituir uma série representativa, atentar para as características de ordem material, caracterizar o grupo responsável pela publicação, identificar os colaboradores, o público que se destina e analisar o material de acordo com a problemática escolhida, neste caso a imigração do pós-guerra ${ }^{4}$.
A análise também foi norteada metodologicamente pela Análise de Discurso desenvolvida no Brasil por Orlandi (2012), oriunda de matriz francesa ${ }^{5}$. Nesta perspectiva, se afirma que o discurso não está apenas na pronúncia, enquanto fala, mas em todas as formas verbais e não verbas. O texto é a materialização desse discurso, em que o simbólico e o político se encontram e desenvolvem as funcionalidades de proposição de sentido. Nas fontes não se encontra um discurso para ser revelado ou "cortina para ser aberta", no texto procuram-se vários discursos a serem inferidos, problematizados e confrontados, a partir dos muitas possibilidades apresentadas, dos seus sentidos ${ }^{6}$.

Para compreender a problemática específica desses imigrantes das décadas de 1940, 1950 e 1960 é necessário apresentar o contexto em que estavam imersos.

A Segunda Guerra Mundial (1939-1945) promoveu o deslocamento voluntário ou não de milhares de pessoas às regiões governadas pela Alemanha Nazista nos campos de trabalhos: sendo esses de concentração, fábricas de armamentos ou atividades domésticas. Conforme o fim da guerra se aproximava, algumas regiões foram libertadas pelo grupo dos aliados, com isso, algumas pessoas retornaram aos seus países de origem. As demais pessoas, que por razões diversas preferiram não retornar, ficaram em campos de acolhimento, principal-

\footnotetext{
${ }^{1}$ Neste artigo foram utilizados alguns elementos da dissertação: Discursos sobre imigração no jornal Folha do Oeste - Guarapuava, Paraná (1946-1960), apresentada ao Programa de Pós-Graduação em História da Universidade Estadual do Centro-Oeste (UNICENTRO)- (SANTOS, 2015).

${ }^{2}$ O periódico foi disponibilizado para o pesquisador pelo Centro de Documentação e Memória de Guarapuava que se encontra no interior da Universidade Estadual do Centro-Oeste (UNICENTRO), Campus Santa Cruz, situada na Rua Padre Salvador, 875 - Santa Cruz, Guarapuava (PR).

${ }^{3} \mathrm{O}$ documento foi consultado no acervo online do Arquivo Público do Estado de São Paulo. Disponível em: http://www.arquivoestado.sp.gov.br/site/ acervo.

${ }^{4}$ Segundo Luca (2014, p. 141): “A variedade da fonte impressa é enorme e as suas possibilidades de pesquisa são amplas e variadas. Assim, não é viável sugerir um procedimento metodológico ou mesmo técnicas de pesquisa que deem conta de tantas possibilidades. Entretanto, vale destacar alguns pontos muito gerais para quem deseja iniciar uma pesquisa nesse campo". Não possuí um único caminho para a pesquisa histórica, cada pesquisa deverá trilhar os seus próprios meios de análise sobre os periódicos, os princípios gerais destacados pela autora referem-se aos procedimentos iniciais, como mencionados no corpo deste artigo.

${ }^{5}$ Orlandi (2012) apresenta a diferença entre Análise de Discurso e Análise do Discurso: "Essa questão se pôs em francês porque a diferença de/du (do) era relevante pois o efeito de sentido com 'de' era de 'um' discurso enquanto 'du' abria para os discursos em geral. A meu ver, em nosso caso, Análise de Discurso produz melhor esse efeito de discurso tomando em geral, como objeto e não como um discurso (do discurso político, do discurso jurídico etc)" (ORLANDI, 2012, p. 55). A autora aponta que a Análise do Discurso, pressupõe um discurso unitário com um único sentido, enquanto a Análise de Discurso propõe a compreensão de vários discursos com muitos sentidos.

${ }^{6} \mathrm{O}$ discurso é uma proposição de sentido, entre tantos possíveis, entretanto, nem toda proposição é válida, existe as limitações do discurso. Segundo Orlandi (2012) existem limites para o discurso, uma gama de possíveis e outros nem tão possíveis. Como exemplo a autora aponta que quando se escreve um texto, às vezes é necessário, apagar os trechos escritos e começar novamente, pois os sentidos possíveis que o autor quer passar para o leitor não foram os atingidos, sendo necessária uma nova escrita, para sua compreensão, por isso, nem todo sentido pode ser considerado válido.
} 
mente na Alemanha, Itália e Áustria. Em seguida, optaram em imigrar para outros países, inclusive o Brasil, sendo auxiliados por órgãos internacionais ${ }^{7}$.

Para inferir os discursos sobre esses imigrantes do pós-guerra esse trabalho se divide em três momentos distintos, mas com conexões. No primeiro momento destacam-se elementos da Segunda Guerra Mundial e do pós-guerra. Em um segundo, destaca-se a fonte pesquisada, o jornal Folha do Oeste. No terceiro momento, analisa-se algumas matérias ${ }^{8}$ do jornal Folha do Oeste que remetem a vinda dos imigrantes neste contexto.

\section{O pós-guerra e a imigração}

É consenso entre os pesquisadores ${ }^{9}$ que se dedicam ao tema imigração a dificuldade de percepção deste fenômeno, para tanto, utilizam-se os elementos propostos por Nogueira (1991), o tempo e a distância. Esse pesquisador apresenta que diferente dos aspectos demográficos (natalidade, fecundidade, mortalidade, entre outros), a migração depende da observação do observador, especialmente das categorias tempo e distância. O tempo em que o estudioso encontra-se e está inserido, pois esse infere nas suas posições teóricas e metodológicas e a distância necessária para a visualização do fenômeno migratório.

Analisando o fenômeno migratório, pautando-se nessa perspectiva de tempo e distância, encontraram-se a imigração no período do pós Segunda Guerra Mundi- al (1946-1960). Neste período, é visualizada uma especificidade de imigração que inicialmente denominou seus sujeitos de deslocados ou refugiados de guerra. Segundo Judt (2008) os deslocados de guerra foram aqueles que tinham para onde voltar depois de terminada à Segunda Guerra Mundial, aqueles que antes da Segunda Guerra foram forçados a deslocar-se para Alemanha e posteriormente seriam recebidos em seus países de origem. Enquanto os denominados refugiados, não poderiam voltar para seus países originários, ou porque seus países não existiam (pela nova divisão europeia), porque nãos seriam aceitos, ou por razões particulares. Apesar dessa divisão apresentada por Judt (2008), o pesquisador enfatiza a dificuldade de classificação entre deslocados ou refugiados de guerra, e que muitos podem encontrar-se pertencentes às duas categorias e outros nenhuma. ${ }^{10}$

Outra pesquisa que aponta informações sobre esses sujeitos é a de Peres (1997, p. 54): “Com o fim da Segunda Guerra Mundial, as atenções das potências voltaram-se para a tarefa de 'reconstrução' da Europa devastada e para o problema dos refugiados de guerra, denominados displaced persons ou DPs". Com o fim da Segunda Guerra Mundial, os deslocados de guerra, também considerados o legado da guerra ${ }^{11}$, ficaram em campos de acolhimento. Posteriormente, alguns conseguiram regressar para sua Pátria de origem, outros desejaram novas pátrias, deslocando-se para os Estados

\footnotetext{
${ }^{7}$ Entre as instituições que auxiliaram os refugiados/deslocados encontram-se o CIR (Comitê Intergovernamental para os Refugiados), a UNRRA (Administração de Socorro e Reabilitação das Nações Unidas), a OIR (Organização Internacional de Refugiados), o CIME (Comitê Intergovernamental para as Migrações Européias), a ACNUR (Alto Comissariado das Nações Unidas para os Refugiados), e algumas organizações religiosas (ANDRADE, 2006; STEIN, 2011).

${ }^{8}$ Com base em Rabaça e Barbosa (2014) percebeu-se a diferença entre nota, reportagem e matéria. A nota é uma informação concisa com pouca profundidade. A matéria é designação genérica para qualquer escrito jornalístico. Enquanto a reportagem é formada a partir de um tratamento cuidadoso do profissional da comunicação: confrontação de dados, entrevistas e a ida no local do eveto. Nos escritos do jornal Folha do Oeste, aqui analisados, visualiza-se que todos são matérias, pois não apresentam um trabalho cuidadoso e a apuração no local do evento.

${ }^{9}$ Além de Nogueira (1991), Brumes (2003) e Schörner (2009) também apresentam a dificuldade de percepção do fenômeno migratório. Outras visões sobre imigração podem ser encontradas no trabalho de Santos, Almeida e Schörner (2014).

${ }^{10}$ Alguns moradores dos campos de acolhimento com receio de sua expulsão, caso fossem descobertos como colaboracionistas promoviam manobras para preservar sua identidade. Entre as manobras, estavam a invenção de histórias de vida, a não declaração de documentos pessoais ou a ocultação da sua identidade pelos interpretes, geralmente amigos. O processo de filtragem ou blindagem como ficou conhecido, o procedimento de seleção nos campos, quando realizado encontrava-se de forma frágil, sendo feito ou aligeirado ou cancelado no meio do processo (SHEPHARD, 2012).

${ }^{11}$ Judt (2008) apresenta um capítulo específico sobre os deslocados/refugiados ( $O$ Legado da Guerra) na sua obra com temática dos anos posteriores da Segunda a Guerra. O autor aponta que além da destruição física (o espaço), a Segunda Guerra deixou como herança milhares de pessoas em campos de acolhimento.
} 
Unidos, Canadá, Austrália, Argentina e Brasil, transformando-se em imigrantes.

Os temas relacionados ao pós Segunda Guerra também foram preocupações de Shephard (2012). O autor apresenta os milhões de sobreviventes judeus, poloneses, ucranianos, letões, lituanos, estonianos e iugoslavos, que permaneceram em campos de acolhimento na Alemanha, Áustria e Itália, não tinham para onde voltar. Cada um desses sujeitos tinha uma história diferente e complexa (do local que ficou durante a guerra), alguns ajudaram a Alemanha Nazista, sendo considerados "inimigos". O que unia esse grande grupo foi que todos tiveram a classificação de Pessoa Deslocada ou refugiada ${ }^{12}$, e posteriormente imigrantes, pois designações como vítima e perpetradores não conseguiam abarcar essa complexidade. ${ }^{13}$

Outra contribuição de Shephard (2012) refere-se ao porque dessa história não ter destaque na historiografia: "Essa história foi em grande parte ignorada pelos historiadores, principalmente porque permanece de forma desconfortável entre grandes nomes como a Segunda Guerra Mundial, a Guerra Fria, o Holocausto e a questão Israel-Palestina" (SHEPHARD, 2012, p. 14). A história desses sujeitos sem Pátria, àqueles que ficaram no pós-guerra em campos de acolhimento, e posteriormente tornaram-se imigrantes nas suas novas pátrias, por muito tempo não foi preocupação dos historiadores.

O termo refugiado também merece mais algumas considerações. Segundo a Convenção Relativa ao Estatuto dos Refugiados $(1951)^{14}$ o refugiado é aquele que encontra-se afastado de sua Pátria por perseguições motivadas por etnia, religião, nacionalidade, grupo social ou opinião política restritas aos anos anteriores a 1951. Apesar disso, perde sua condição de refugio ao conseguir a garantia (cidadania) do país que o acolheu. Diante disso, esse refugiado ao encontrar uma nova morada não garante mais sua condição internacional de refúgio, por outro lado, ainda possui sua condição de imigrante, como aponta a OIM (2009, p. 33) sobre o processo de imigração: "Processo através do qual estrangeiros se deslocam para um país, a fim de aí se estabelecerem". O sujeito, mesmo que receba a naturalização do novo país, continuará sendo visto como um imigrante, um estrangeiro que veio de uma localidade que não é a sua, por motivações e razões diversas ${ }^{15}$. Nesse período um imigrante do pós-guerra, pois se originou de um contexto específico, por motivações decorrentes da Segunda Guerra Mundial.

Ao chegar as suas novas casas, segundo Peres (1997), esses imigrantes, oriundos da destruição do pós -guerra foram recebidos com hostilidade, sendo denominados de egressos de guerra, psicopatas incubados, alienígena, bom ou mau elemento, desejável ou indesejável, reprodutor, perigo iminente, seres nefastos, indesejáveis, neuróticos de guerra, parasitas humanos, imprestáveis, entre outros. ${ }^{16}$

Depois de visualizar algumas discussões do pós Segunda Guerra Mundial adentra-se, especificamente nas características da fonte estudada, os jornais, como eles foram percebidos nos estudos históricos e se apresenta o jornal guarapuavano Folha do Oeste, em que

\footnotetext{
${ }^{12}$ Na versão brasileira, a obra de Shephard (2012) apresenta o termo Pessoas Deslocadas (PDs) como sinônimo para Displaced persons (DPs).

${ }^{13}$ Shephard (2012) apresenta a dificuldade de julgamento dos sujeitos que auxiliaram as práticas nazistas, pois muitos tiveram isso como última alternativa, forma de sobreviver, essas ações. Outros foram atraídos pela propaganda. Conforme Prost (2008) a função do historiador não é o julgamento das ações dos sujeitos no tempo, mas a sua compreensão, a partir das práticas sociais.

${ }^{14}$ A Convenção relativa ao Estatuto dos Refugiados foi concluída em 28 de julho de 1951 em Genebra na Suíça. Segundo Andrade (2006) os Estados que aderiram à convenção se comprometeram em não devolver os refugiados a qualquer país que sua vida, liberdade ou integridade física estivesse ameaçada, apesar disso, a convenção não apresentou nenhuma punição aos países que a descumprirem.

${ }^{15}$ Segundo Seyferth (2008,p.3): "Imigrante, num sentido mais geral, é aquele que se desloca para outro país e ali permanece, e a imigração tem sido qualificada justamente pela entrada de indivíduos ou grupos num país estrangeiro com intenção de ali restabelecer sua residência".

${ }^{16}$ Uma discussão sobre a denominação de alienígena para os imigrantes pode ser encontrada em Santos, Almeida e Schörner (2015).
} 
posteriormente será problematizada a imigração do pósguerra.

\section{O jornal Folha do Oeste}

Segundo Luca (2014) a imprensa, inclusive a imprensa periódica é rica para a percepção de fenômenos históricos, apesar de sua descoberta tardia, na década de 1970. Até os anos de 1930 acreditava-se na impossibilidade de fazer uma história com os periódicos, até porque os consideravam com pouca objetividade, neutralidade e fidedignidade, pela sua escrita no calor do momento. A partir de 1930 outras fontes foram incorporadas a escrita da história pela historiografia francesa, especialmente pelo grupo francês Annales. A primeira geração desse grupo preocupou-se, principalmente com os estudos medievalistas, a segunda com a abordagem serial, apenas a terceira percebeu a imprensa como fonte para desenvolver estudos históricos.

Os estudos sobre imigração e imprensa também foram preocupação de Dreher (2004), a partir de duas formas de visualizá-los. Uma das formas refere-se à representação dos mesmos pela imprensa brasileira, e a outra como esses foram verificados nos periódicos criados por eles, em sua maioria jornais na língua de origem, como forma de organização e agrupamento de mesma etnia.

Neste artigo para a visualização do movimento imigratório para o Brasil no pós- Segunda Guerra Mundial utiliza-se o jornal Folha do Oeste, produzido no Município de Guarapuava-PR de 1937 a $1981^{17}$. Antes de adentrar-se aos aspectos imigratórios, são relevantes algumas informações sobre o jornal para perceber sua posição partidária e suas influências nas sociedades guarapuavana, paranaense e brasileira. Duas pesquisas apresentaram sistematicamente alguns elementos sobre o jornal Folha do Oeste e seu fundador Antonio Lustosa de Oliveira, sendo elas a de Maria (2011) e Silva (2010).

A historiadora Silva (2010) retratou além do jornal Folha do Oeste a trajetória de seu fundador, o influente político e empresário Antonio Lustosa de Oliveira. Lustosa fundou alguns jornais ${ }^{18}$, e assumiu vários cargos políticos: Deputado Estadual e Federal, Prefeito, Presidente da Caixa Econômica no Paraná e Presidente do Diretório Estadual do Partido Socialista Democrático (PSD). Como empresário além de proprietário do jornal Folha do Oeste, possuía a Gráfica Guairacá e a Rádio Difusora de Guarapuava.

O pesquisador Maria (2011) destaca que o referido periódico foi mais importante jornal produzido em Guarapuava até 1970, apresentando inovações para a sociedade guarapuavana. Uma dessas inovações encontra-se na qualidade técnica, as edições além de serem claras e organizadas, encontram-se publicações de fotos, inovação inédita no município pela sua dificuldade de produção, mesmo sendo totalmente em preto e branco. Outra inovação da Folha do Oeste é sua capa que possui uma notícia política e nas páginas seguintes, matérias ou reportagens econômicas, políticas, sociais, religiosas, dispostas de forma aleatória.

Na mesma esteira de Maria (2011) a pesquisadora Silva (2010) ressalta que o semanário foi o mais significante jornal fundado por Lustosa, pela sua publicação estendida (mais de quarenta anos), circulação por vários Estados e que por meio dele se analisa eventos

\footnotetext{
${ }^{17}$ O jornal Folha do Oeste foi dividido, pelos seus editores em fases, cada parada e recomeço de publicação originava uma nova fase. Até 1960 encontrava-se na quarta fase.

${ }^{18}$ Segundo Maria (2010) os empreendimentos de Antonio Lustosa de Oliveira com publicação iniciaram em 1919, quando ele instalou uma tipografia para impressos comerciais e lançou as publicações de: Pharol, Brasilidade e Movimento, todos com curta duração, posteriormente o Folha do Oeste.
} 
em várias escalas ${ }^{19}$. O periódico apresenta eventos nacionais, estaduais e locais, destacando aspectos tanto do percurso político do seu fundador como os efeitos dos acontecimentos do período de sua abrangência.

O jornal Folha do Oeste também torna-se relevante por ser uma fonte rica para a percepção das ações relacionadas aos imigrantes do pós Segunda Guerra Mundial, visualizados em seu período de existência, por apresentar matérias sobre a temática. Os eventos nacionais sobre imigração são as observações demonstradas nos parágrafos seguintes deste trabalho.

\section{A imigração nas páginas do Folha do Oeste}

Algumas matérias do jornal Folha do Oeste apresentam ações para a imigração no pós-Segunda Guerra Mundial. Entre as matérias encontra-se uma reunião entre o Ministro João Alberto (presidente do Conselho Nacional de Imigração) e jornalistas no Rio de Janeiro: “O Ministro João Alberto, reuniu, há poucos dias no seu gabinete, alguns jornalistas do Rio de Janeiro, e com eles palestrou largamente sôbre a corrente imigratória que se processa para o Brasil, de cerca de 100.000 europeu" (FOLHA DO OESTE, 11/08/1946) ${ }^{20}$. Neste trecho evidencia-se o porquê da reunião realizada com jornalistas do Rio de Janeiro, por essa localidade ser a Capital Federal até 1960, com isso, facilitando a difusão das informações para todos os Estados da Federa- ção ${ }^{21}$. Outro aspecto relevante desse trecho refere-se à cifra de 100.000 imigrantes no pós-guerra encaminhados ao Brasil, esse número não foi o de recebimento dos imigrantes, foram apenas estimativas das autoridades brasileiras como aponta Salles ([et. al], 2013) ${ }^{22}$.

Em outro trecho a matéria menciona o interesse do Brasil pela imigração: "O Presidente do Conselho Nacional de Imigração [...] tratou da situação dos chamados $<$ displaced persons $>$ [...] e da necessidade que temos de braços e técnicos especializados, para o desenvolvimento das nossas industrias e da nossa lavoura" (FOLHA DO OESTE 11/08/1946). Os imigrantes teriam como função auxiliar nas atividades da indústria e agricultura brasileira, devido à necessidade do país em técnicos especializados para essas ações. Essa afirmativa objetivava resolver o problema brasileiro de carência de alimentos e de técnicas industriais. ${ }^{23}$

Em outra matéria os imigrantes tinham como função para o governo brasileiro suprirem a necessidade da indústria e da lavoura, junto com outras demandas: "Consignando êsse fato não é de mais lembrar-se a necessidade premente de cobrir os claros demográficos abertos na agricultura, na indústria que se expande e no comércio que procura se adaptar às realidades do após guerra" (FOLHA DO OESTE, 06/06/1949). Os imigrantes viriam para trabalhar na indústria, agricultura e realizar operações comerciais ${ }^{24}$. A pesquisadora Peres

\footnotetext{
${ }^{19}$ O Folha do Oeste igualmente foi relevante por circular em várias localidades. Apesar da maioria de suas publicações ficarem no Município de Guarapuava foi distribuído em Foz do Iguaçu, Cascavel, Toledo, Guairá, Guaraniaçú, Laranjeiras, Pitanga, Campo do Mourão, Prudentópolis, Imbituva, Irati, Palmeira, Campo Largo, Jaguariaiva, W. Braz, Londrina, Maringá, Rolândia, Assaí, Cornélio Procópio, Monte Alegre, Ponta Grossa, Curitiba, Antonina, Paranaguá, Cerro Azul, Pato Branco, Palmas, União da Vitória, Paranavaí, Apucarana, Porecatú, Astorga, Lapa, Porto Amazonas, Ibaiti, Rio Negro e Nova Londrina. Em Santa Catarina - Caçador, Videira, Joaçaba, Xaxim, Xapecó, Curitibanos, Lages, Porto União, Taió e Rio do Sul. Em São Paulo Capital. Goiás: Ferreiros. Rio de Janeiro: Capital Espírito Santo - Colatina e Calçado. No Rio Grande do Sul - Santa Maria, Passo Fundo, Carasinho e Guarany das Missões. Em Minas Gerais- Paracatu, Três Corações e Uberlândia (FOLHA DO OESTE, 11/09/1955).

${ }^{20}$ Nas citações do periódico Folha do Oeste e das demais fontes foram preservadas as grafias originais das décadas de 1940 e 1950.

${ }^{21}$ O Rio de Janeiro foi Capital Federal até 1960, quando foi inaugurada Brasília pelo Presidente Juscelino kubitschek.

${ }^{22}$ Segundo Salles ([et. al], 2013) no pós guerra o Brasil recebeu 22.009 imigrantes, estabelecidos em sua maioria em São Paulo. Foram 11.079 em São Paulo, 4.606 no Paraná, e o restante em outros estados.

${ }^{23}$ Um exemplo da motivação para resolver a escassez alimentar é a imigração dos Suábios do Danúbio ao Município de Guarapuava-Paraná em 1951. Esses imigrantes vieram para suprir a carência de trigo no Estado. Ver Stein (2011). O discurso de auxílio internacional para o nacional é apontado em alguns edições do jornal Folha do Oeste como: "É o Brasil dos imigrantes distantes - alemães, polacos, italianos, japoneses e tantos outros, que para cá vieram, a fim de melhorar sobreviver, [tra] balhando a terra e dela arrancando o pão nosso de cada dia! Imigrantes, que sempre contaram com a tradicional hospitalidade brasileira e assistência amiga de seus cônsules!" (FOLHA DO OESTE, 18/10/1957, p. 1).

${ }^{24}$ O jornal Folha do Oeste também destaca a presença de imigrantes Sírios no Município de Guarapuava, em instalações comerciais, praticando preços considerados pelos demais como abusivos (FOLHA DO OESTE, 16/01/1949, p. 1).
} 
(1997) apresenta que além dessas funções os imigrantes auxiliariam na reprodução brasileira ${ }^{25}$. A autora destaca que os imigrantes possuíam a missão de branquear a população brasileira, por isso, seriam bem vindos, especialmente os que se apresentavam saudáveis para gerar descendentes. Esse pressuposto lembra vestígios da política de branqueamento do final do século XIX e início do XX.

Outro aspecto da matéria de 1946 refere-se à distribuição dos imigrantes em território nacional:
Mas, . - sempre um mas... O Snr. João Alberto encerrou a palestra no ponto nevrálgico da questão, justamente naque- le em que todo o Brasil, de mãos conco- vas ao ouvido, se apresentava para escu- tá-lo: Como pretende o Conselho de Imi- gração distribuir os deslocados que ire- mos hospedar?
Ai que está o buzilis da questão! (FOLHA DO OESTE, 11/08/1946).

A matéria apresenta a dificuldade de distribuição dos imigrantes, e que essa seria uma questão importante para ser tratada pela reunião. Um assunto essencial que o Ministro/Presidente do Conselho Nacional de Imigração não conseguiu resolver, sendo o ponto final de sua palestra, uma fenda aberta. Ele não aponta sugestões sobre como distribuir esses imigrantes, se seriam reunidos em núcleos ou distribuídos separadamente; em si, não afirma efetivamente a disposição dos imigrantes do pós-guerra na sociedade Brasil.

No discurso dessa matéria é interessante demonstrar os aspectos de Orlandi (2012) sobre pontuação ${ }^{26}$. A pontuação auxilia na proposição de sentido de um texto, as vírgulas, ponto de interrogação e exclamação complementam o sentido. Nesse trecho do jornal isso é evidente, enfatiza-se uma dificuldade com relação aos imigrantes, onde deveriam ser hospedados e destaca a partir de um jargão popular o buzilis, a dificuldade da questão sem solução. Apesar de apresentar o problema não aponta a solução, a incompletude do discurso.

Essa matéria, ainda destaca outras questões sobre imigração: "Querem trabalhar conosco? Querem nos ajudar? Demo nos ás mãos e nós os ajudaremos também. A casa, porém, é nossa. Nós, é que lhes diremos quais os aposentos em que poderão ficar...” (FOLHA DO OESTE, 11/08/1946). Os imigrantes viriam para trabalhar para os brasileiros, ajudar; em nenhum momento seriam independentes, pois os imigrantes são considerados intrusos, alheios a realidade brasileira, os brasileiros que escolheriam onde esses poderiam ficar. Caso contrário eles não seriam bem vindos, não sendo aceitos.

Outra matéria que apresenta outros imigrantes: "Festejando a obtenção do título declaratório de nacionalidade brasileira, os snrs. José Krupa e Pedro Foganóli, oferecem á sociedade guarapuavana, domingo último, suculento churrasco, na sede da Sociedade Operária, desta, cidade" (FOLHA DO OESTE, 16/06/1946). É importante destacar que os imigrantes, sentem o anseio de fazer parte da sociedade que escolheu para morar, incorporar-se ao novo meio, pois se sentem provisórios, precisando de uma legitimidade para permanecendo como definitivos:

Na medida em que a presença do imigrante é uma presença estrangeira ou que é percebida como tal, as 'ilusões'

\footnotetext{
${ }^{25}$ A pesquisadora Peres (1997, p.87) apresenta que "aparece como sendo de extrema importância a questão do potencial reprodutor do imigrante. Fala-se em braços para a lavoura e a indústria, mas também em 'sangue novo' ou 'plasma de reprodução', acreditando-se que os imigrantes viriam 'aduzir sangue novo à nossa etnia', como afirmou Fernando Mibielli de Carvalho no artigo 'Imigração: um problema nacional".

${ }^{26}$ Segundo Orlandi (2012, p. 122-123): “o ponto final [.] exclui o que não está lá (mas em outro lugar). No espaço, ele marca a extensão mínima do corpo do texto. A vírgula [,] não sendo uma parada radical (como o ponto final) é signo da des-ligação (sic) em relação ao interdiscurso, fazendo intervir a passagem por 'outros' discursos, abrindo para outros sentidos. O ponto e vírgula [;] indica acúmulo, alargamento, limites fluídos em que a ambigüidade parodia o equivoco [...] As reticências [...] mostram, na incompletude, um acréscimo não preenchido. Presença de um acréscimo ausente, as reticências [...] são um lembrete de um acréscimo”. A pontuação tem um papel fundamental nas inferências apresentadas em um discurso, em sua forma de texto.
} 
que a ela estão associadas e que até mesmo a constituem podem ser enunciadas como segue: são, para começar, a ilusão de uma presença necessariamente provisória (SAYAD, 1998, p. 18).

O imigrante mesmo que esteja morando muitos anos no país que escolheu para viver, neste caso Krupa e Foganóli mais de vinte e cinco anos, em sua terra de destino serão considerados estrangeiros. As pessoas que habitam anteriormente o espaço não o reconhecem como permanente, sempre os denominado de imigrantes, num espaço provisório. O que Sayad (1998) denominou de paradoxo da migração, ausência onde se encontra presente (destino), e presença onde se encontra fisicamente ausente (origem).

Retornando a matéria destes imigrantes, percebem-se suas trajetórias. Primeiro do Sr. José Krupa: “O snr. José Krupa é natural da Ukrania, chegou ao Brasil em 1927, tendo residido algum tempo em Curitiba, transportou-se depois para Guarapuava, onde fixou residência e contraiu matrimonio com a exma. Sra. D. Apolinária Denega" (FOLHA DO OESTE, 16/06/1946). Em seguida, o Sr. Pedro Foganóli: “O Sr. Pedro Foganóli, nasceu na Itália. É construtor de rara competência, sendo autor de inúmeras e custosas construções nesta cidade" (FOLHA DO OESTE, 16/06/1946). Esses imigrantes não vieram no pósguerra, mas no que foi denominado de primeiro período da imigração brasileira ${ }^{27}$. O imigrante José Krupa tem sua origem ucraniana e o Pedro Foganóli italiana, am- bos do continente europeu. Chama atenção a necessidade da matéria em ressaltar alguns aspectos considerados benéficos desses imigrantes, o primeiro de reimigrante, depois de residir em Curitiba veio para Guarapuava, casando-se com uma gurapuavana. O segundo, Sr. Foganóli, têm habilidades com construções, possivelmente a matéria infere pelo discurso que trouxe a técnica do continente europeu, portanto, para o dito nacional o imigrante precisava de uma qualidade para habitar terras brasileiras. Essa disputa entre imigrantes e nacionais motivou outras discussões no jornal Folha do Oeste. ${ }^{28}$

Outra matéria sobre imigração no jornal Folha do Oeste aponta como viriam esses imigrantes, por um novo meio de transporte: "É das mais auspiciosas a notícia de que vamos receber, semanalmente, imigrantes por via aérea" (FOLHA DO OESTE, 05/06/1949). O transporte aéreo não diminui o transporte por via marítima: "concomitantemente, com os embarques marítimos, venha, por via aérea, em ritmo semanal, um determinado número de imigrantes" (FOLHA DO OESTE, 05/06/1949). Os imigrantes viriam de forma marítima e aérea semanalmente. Além disso, "o serviço de transporte aéreo começará imediatamente" (FOLHA DO OESTE, 05/06/1949). O governo brasileiro possuía urgência em receber imigrantes.

O transporte de imigrantes por via aérea também é visualizado em um processo da Delegacia de Ordem Social de Santos - SP (DOPS) ${ }^{29}$ :

\footnotetext{
${ }^{27}$ Segundo Salles e Bastos (2012) o Brasil viveu quatro momentos distintos de imigração: o primeiro, com o maior número de imigrantes (substituição de mão de obra escrava pela imigrante) até 1906; o segundo até a Primeira Guerra Mundial (1914); o terceiro até o Fim do Estado Novo (1945); e o quarto do pós Segunda Guerra Mundial (1946) até os dias atuais.

${ }^{28}$ A matéria de 13 de outubro de 1957, intitulada Um imigrante sem cônsul! do jornal Folha do Oeste reclama que o imigrante recebeu mais atenção que os nacionais em solo brasileiro, principalmente recebendo sementes e insumos do governo. Ainda, nesta discussão outros jornais do período apresentam que os imigrantes encaminhados para o Brasil concorriam com os nacionais em atividades de comércio como loterias: "IMIGRANTE- deslocados de todas as partes do mundo são enviados como imigrantes. Aqui êles se ocupam de profissões parasitárias, vendendo bilhetes, gravatas ou fazendo negócios excusos" (DIÁRIO DO PARANÁ, 06/05/1955, p.1).

${ }^{29}$ O processo $\mathrm{n}^{\circ} .5994$ de 30 de junho de 1950 refere-se ao russo Theodor Korsch. Esse sujeito na sua travessia para o Brasil foi interceptado e ficou detido por apresentar dois endereços de residência no país: "THEODOR KORSCH, que diz trabalhar para a ORGANIZAÇÃO INTERNACIONAL DOS REFUGIADOS no Brasil, com escritório central no Rio de Janeiro, à AV. Getulio Vargas nº. 446, esteve em São Paulo há poucos dias, regressando ao Rio de Janeiro de avião. Ao embarcar, em Congonhas, disse residir em São Paulo, à Av. Altino Aranhes n 389, Vila Mariana. Ao embarcar no Rio de Janeiro, a bordo do navio 'Protéa', THEODOR KORSCH deu seu endereço completamente diferente, pois disse, nessa ocasião que residia em São Paulo à Av. Tesiner n n 309” (ARQUIVO DE SÃO PAULO, 1950). Outras acusações foram ao russo foram a posse de duas máquinas fotográficas e revistas comunistas.
} 
Chegou ontem a este porto, procedente de Napoli e com destino a Buenos Aires, o navio panamenho 'Protea', que trouxe a bordo 263 refugiados de guerra de nacionalidades polonesa, russa, tcheca, iugoslava, ucraniana e sem nacionalidade. Esses refugiados, que se destinam ao Paraguai, desembarcaram neste porto e seguiram para São Paulo em trem especial da Estrada de Ferro Santos a Jundiai. Segundo informações colhidas por esta chefia, esses refugiados ficarão concentrados em Campo Limpo ate o dia em que seguirão para o Paraguai, sendo que a viagem de São Paulo ao Paraguai será feita de avião (ARQUIVO DE SÃO PAULO, 1950).

Os imigrantes, como é mencionado no processo, poderiam serem transportados por via marítima, aérea ou de forma mista, até o seu destino final. No fragmento acima, são 263 imigrantes de diversas nacionalidades (polonesa, russa, tcheca, iugoslava, ucraniana e sem nacionalidade $)^{30}$, oriundos do navio panamenho Protea que tinham como destino a Argentina, Buenos Aires. O trajeto do Porto de Santos até Jundiaí seria feita por um trem especial e depois ficando concentrados na localidade de Campo Limpo. Em seguida, iriam de avião de São Paulo até o Paraguai e de lá para a Argentina. Esse último trajeto não foi explicado no processo.

Os imigrantes italianos, especificamente agricultores também tinham interesses em vir para o Brasil: "Dentre os candidatos que se oferecem [...] há duzentos agricultores solteiros e numerosas famílias com a média de oito a dez pessoas, todos afeitos aos labores da terra” (FOLHA DO OESTE, 26/08/1951). Os números apontam duzentos agricultores que poderiam vir para o Brasil e mais algumas famílias, o número de famílias não fica explícito. A diferença entre os solteiros e os casados, que os primeiros tinham recursos para o transporte: "Os duzentos agricultores solteiros dispõe de re- cursos para o transporte marítimo e poderão embarcar imediatamente, desde que contem com a garantia de um contrato de trabalho que lhes assegure colaboração favorável” (FOLHA DO OESTE, 26/08/1951). Enquanto os casados, os grupos familiares: "Os grupos familiares, porém não poderão custear suas passagens" (FOLHA DO OESTE, 26/08/1951). Os imigrantes viriam por meio marítimo, podendo embarcar imediatamente, desde que se garanta para os mesmos um contrato de trabalho, ou seja, garantia de rendimentos. Os solteiros teriam dinheiro para o custeio do transporte, não precisando o governo brasileiro ou proprietários brasileiros custear seu translado, enquanto os casados deveriam contar com essa forma de auxílio.

Essa matéria também apresenta o procedimento de vinda desses imigrantes italianos:
O conselho de Imigração e Colonização, ao divulgar essa informação, terá a má- xima satisfação em receber propostas concretas e objetivas dos proprietários brasileiros que pretenderem esse exce- lente braços agrícolas afim de transmiti- las ao seu representante na Europa [...] tais propostas fossem encaminhadas di- retamente ao Departamento Nacional de Imigração no Ministério do Trabalho, por intermédio da Secretaria de Agricul- tura, Indústria e Comércio do Estado do Paraná (FOLHA DO OESTE, 26/08/1951).

A vinda destes imigrantes agricultores italianos só seria efetivada se tivesse fazendeiros brasileiros interessados que poderiam recebê-los, caso contrário, ficariam onde se encontravam. $\mathrm{O}$ processo burocrático brasileiro dificultava a vinda desses novos moradores, o interesse por eles deveria ser feito por um comunicado ao Departamento Nacional de Imigração por intermédio da Secretaria de Agricultura, Indústria e Comércio do Paraná. Nesse trecho, ainda chama atenção as propos-

\footnotetext{
${ }^{30}$ Sem nacionalidade ou apátrida segundo a Organização Internacional para Migrações (OIM, 2009, p. 8): "Pessoa que não seja considerada por qualquer Estado, segundo a sua legislação, como seu nacional (art. 1. ${ }^{\circ}$ da Convenção da ONU sobre o Estatuto dos Apátridas, de 1954). Como tal, faltam ao apátrida os direitos decorrentes da nacionalidade: a protecção diplomática do Estado, nenhum direito inerente permanência no Estado da residência e nenhum direito de regresso caso decida viajar". Apátrida é o sujeito não considerado cidadão de nenhum país, sem cidadania.
} 
tas concretas e objetivas, o interesse pelos imigrantes deveria ser efetivo e com toda a logística proposta e posteriormente executada pelos proprietários brasileiros, caso fosse feita a opção pelos solteiros eles pagariam o translado, se fossem os casados, o pagamento se daria pelos proprietários das fazendas.

O discurso nessa matéria evidencia como em outras, que o governo brasileiro tinha interesse pela vinda dos imigrantes de diversas partes do continente europeu, mas possuía alguns entraves, questões burocráticas e logísticas. Entre as dificuldades encontravamse questões financeiras, o Estado não conseguia sozinho custear a vinda dos imigrantes, precisava do auxílio da iniciativa privada, no caso da última matéria citada, precisava que os fazendeiros mostrassem interesses e custeassem o translado dos imigrantes. $\mathrm{O}$ auxílio para a vinda dos imigrantes poderia ser feita também por convênios entre o governo brasileiro e organizações internacionais, interessadas em outro lugar para os habitantes dos campos de acolhimento.

\section{Considerações}

Esse trabalho evidencia a dificuldade o contexto de imigração compreendido entre 1946 e 1960 nas matérias do jornal Folha do Oeste, produzido no Município de Guarapuava-PR. Pautados nessas matérias e na afirmativa de Peres (1997) percebe-se que a relação entre imigrante e o dito nacional nem sempre foi amistosa. Em alguns momentos recebendo denominações, em sua maioria, pejorativas como alienígenas, neuróticos de guerra, entre outras.

Além disso, nessas matérias visualizou-se que em alguns momentos a vinda de imigrantes estava condicionada a função de auxílio aos brasileiros, os imigrantes não seria protagonistas de sua vida, mas auxílio aos na- cionais, especialmente nas áreas de agricultura e indústria, ou ainda, realizariam pequenas atividades no comércio.

Os discursos se relacionam com outros discursos, os imigrantes do pós-guerra dialogaram com outros imigrantes. Em uma das matérias do Folha do Oeste encontraram-se imigrantes das primeiras levas de imigração para o Brasil, o Sr José Krupa e o Sr. Pedro Foganóli, que foram representados juntamente com os imigrantes do pós-guerra, mas que sua relação com a guerra é diferente, acompanharam a destruição do continente europeu em solo brasileiro. Esses imigrantes possuíam características de reimigração, ou seja, vieram inicialmente para uma localidade brasileira, possivelmente não se adaptaram e procuram uma nova para se instalar, sendo essa última o Município de Guarapuava-PR.

A vinda dos imigrantes por via aérea pode ser outra percepção desse artigo, também observada no referido periódico. Constatou-se na matéria de 5 de junho de 1949 que os imigrantes a partir do referido ano vieram intercalados por transporte marítimo e por aéreo. O processo da Delegacia de Santos também comprova este fato, que o transporte dos imigrantes poderia ser feito por meio marítimo, aviões ou misto.

Por fim, apresenta-se a dificuldade de incorporação dos imigrantes a nova sociedade, com base na matéria de 16 de junho de 1946 e com os elementos de Sayad (1998), percebe-se que o imigrante sempre será um estrangeiro, nunca perderá esse status. A lembrança da denominação imigrante sempre se fará presente, mesmo depois de vinte e cinco anos, um provisório em sua morada que deveria permanente. 


\section{Referências bibliográficas}

ANDRADE, José Henrique Fischel de. A política de proteção a refugiados da organização das Nações Unidas: sua gênese no período pós-guerra (1946-1952). 2006. 327f. Tese (Doutorado em Relações Internacionais) - Instituto de Relações Internacionais, Universidade de Brasília (UNB), Brasília.

BRUMES, Karla Rosário. Movimentos migratórios em cidades médias: o caso de Uberlândia-MG (1970-2000). 2003. 175 f. Dissertação (Mestrado em Geografia). Universidade Estadual Paulista, Presidente Prudente.

DREHER, Martin N. Apresentação. In: ; RAMBO, Arthur Blásio (org.). Imigração \& Imprensa. Porto Alegre: EST, 2004.

JUDT, Tony. Pós Guerra: uma história da Europa desde 1945. Rio de Janeiro: Objetiva, 2008.

LUCA, Tânia Regina de. História dos, nos e por meio dos periódicos. In: PINSKY, Carla Bassanezi. Fontes Históricas. São Paulo: Contexto, 2014.

MARIA, Maurício de Fraga Alves. Crônicas da alta sociedade: Discursos, representações e cotidiano nas colunas sociais do jornal Folha do Oeste (Guarapuava, PR, 1959-1964). 2011. 137 f. Dissertação (Mestrado em História) Faculdade de Ciências e Letras, Universidade Estadual Paulista, Assis.

NOGUEIRA, Olioto José Oliveira. Migrações Internas: tentativas de buscar uma teoria. Análise e Conjuntura. Belo Horizonte, v. 6, n.1, p. 38-47, jan/abr, 1991.

ORGANIZAÇÃO INTERNACIONAL PARA AS MIGRAÇÕES - OIM. Direito internacional da migração: Glossário sobre migração. Genebra: OIM, 2009. Disponível em: <http://www.acidi.gov.pt/_cf/102363> Acesso em: 18 jun. 2015.

ORLANDI, Eni P. Discurso e Texto: formulação e circulação dos Sentidos. Campinas: Pontes Editores, 2012.

PERES, Elena Pájaro. "Proverbial Hospitalidade"? A Revista de Imigração e Colonização e o discurso oficial sobre o imigrante (1945-1955). Acervo, v. 10, n. 2, p. 55-70, jul/dez 1997. Disponível em: <http://linux.an.gov.br/ seer/index.php/info/article/view/292/254> Acesso em: 19 jun. 2015.

PROST, Antoine. Doze lições sobre a História. Belo Horizonte: Autêntica, 2008.

RABAÇA, Carlos Alberto; BARBOSA, Gustavo Guimarães. Dicionário essencial de comunicação. Lexikon, 2014.

SALLES, Maria do Rosário Rolfsen; BASTOS, Sênia Regina. Política imigratória e imigração italiana no PósSegunda Guerra Mundial: Perfil das entradas e trajetórias. In: TEIXEIRA, Paulo Eduardo; BRAGA, Antonio Mendes da; BAENINGER, Rosana Braga (org.). Migrações: Implicações passadas, presentes e futuras. Marília: Oficina Universitária; São Paulo: Cultura Acadêmica, 2012.

SALLES, Maria do Rosário Rolfsen [et. al] (org.). Imigrantes Internacionais no Pós-Segunda Guerra Mundial. Campinas: Núcleo de Estudos de População - Nepo/Universidade Estadual de Campinas, Faculdade Anhembi Morumbi, Universidade Federal de São Paulo, 2013.

SANTOS, Rodrigo dos. Discursos sobre imigração no jornal Folha do Oeste - Guarapuava, Paraná (1946-1960). 2015. 115f. Dissertação (Mestrado em História)- Universidade Estadual do Centro-Oeste (UNICENTRO), Irati. Disponível em: $\quad<$ http://www2.unicentro.br/ppgh/files/2015/07/ Disserta_o_de_Rodrigo_dos_Santos_562a8c0985c01.pdf>. Acesso em: 6 jun. 2016.

SANTOS, Rodrigo dos; ALMEIDA, Marisangela Lins de; SCHÖRNER, Ancelmo. Os alienígenas do pós-guerra: percepções sobre os Displaced Persons entre 1945 e 1960. In: V Colóquio Nacional Cultura e Poder. Anais. Campo Mourão - PR. 2015. p. 268-280. Disponível em: <http://www.fecilcam.br/culturaepoder/wp-content/ uploads/2015/06/Anais-VColoquio.pdf >. Acesso em: 18 jun. 2015. 
, Apontando regiões nos estudos (i) migratórios. In: VII Seminário Estadual de Estudos Territoriais e II Jornada dos Pesquisadores sobre a questão agrária no Paraná, 2014, Ponta Grossa - PR. Anais do VII SEET. Ponta Grossa - PR: Universidade Estadual de Ponta Grossa, 2014, p. 1-12. Disponível em: <http://www3.uepg.br/ seet/wp-content/uploads/sites/5/2014/08/APONTANDO-REGI\%C3\%95ES-NOS-ESTUDOS-IMIGRAT\%C3\% 93RIOS.pdf> .Acesso em: 19 jun. 2015.

SAYAD, Abdelmalek. A imigração ou os Paradoxos da Alteridade. São Paulo: Editora da Universidade de São Paulo, 1998.

SCHÖRNER, Ancelmo. Paranaenses em movimento: trajetórias e travessias migratórias (1980-2000). Guarapuava: UNICENTRO, 2009.

SEYFERTH, Giralda. Imigrantes, estrangeiros: a trajetória de uma categoria incomoda no campo político. In: $26^{\mathrm{a}}$ Reunião Brasileira de Antropologia. Porto Seguro-BA. Anais da $26^{a}$ RBA. Porto Seguro-BA. 2008. p. 1-20. Disponível em: $<$ http://www.abant.org.br/conteudo/ANAIS/CD_Virtual_26_RBA/mesas_redondas/trabalhos/MR\% 2012/giralda\%20seyferth.pdf $>$. Acesso em: 06 jun. 2016.

SHEPHARD, Bem. A longa estrada para casa: restabelecendo o cotidiano na Europa devastada pela guerra. São Paulo: Paz e Terra, 2012.

SILVA, Walderez Pohl da. De Lustosa a João do Planalto: A Arte Política na Cidade de Guarapuava (19301970). Guarapuava: UNICENTRO, 2010.

STEIN, Marcos Nestor. O oitavo dia: produção de Sentidos Identitários na Colônia Entre Rios - PR (segunda metade do século XX). Guarapuava: UNICENTRO, 2011.

\section{Fontes}

ARQUIVO DE SÃO PAULO - DELEGACIA DE ORDEM POLÍTICA E SOCIAL - SANTOS (DOPS). Prontuário $n^{o}$. 5994 de 30 de jun. 1950. Disponível em: <http://www.arquivoestado.sp.gov.br/memoriapolitica/ prontuario.php?prontuario=BR_SP_APESP_DEOPS_SAN_P005994_01> Acesso em: 18 jun. 2015.

CONVENÇÃO RELATIVA AO ESTATUTO DOS REFUGIADOS, 1951. Disponível em: <http:// www.acnur.org/t3/fileadmin/Documentos/portugues/BDL/

Convencao_relativa_ao_Estatuto_dos_Refugiados.pdf?view=1>. Acesso em: 13 abr. 2015

FOLHA DO OESTE (Acervo do Centro de Documentação e Memória de Guarapuava/PR- CEDOC/G- UNICENTRO).

Hemeroteca Digital da Biblioteca Nacional- jornal Diário do Paraná. Disponível em: <http://bndigital.bn.br/ hemeroteca-digital/> . Acesso em: 6 jun. 2016. 